\title{
Preparation of activated carbon from date palm trunks for removal of eosin dye
}

\author{
Eman Alzahrani ${ }^{*}$ and N. R. A. El-Mouhty ${ }^{1,2}$
}

1Chemistry Department, Faculty of Science, Taif University, 888-Taif, Kingdom of Saudi Arabia

2 Labelled Compounds Department, Hot Laboratories Center, P.O. Box 13759, Egypt

E-mail: em-s-z@hotmail.com

\begin{abstract}
Date palm trees are abundant and cheap natural resources in Saudi Arabia. In this study, an activated carbon was prepared from palm trunks by chemical processes. The chemical activation was performed by impregnation of the raw materials after grinding with $\mathrm{H}_{3} \mathrm{PO}_{4}$ solution (63\%), followed by placing of the sample solution on a muffle furnace at 400 ${ }^{\circ} \mathrm{C}$ for $30 \mathrm{~min}$, and then at $800{ }^{\circ} \mathrm{C}$ for $10 \mathrm{~min}$. The morphology of the fabricated material was checked using scanning electron microscopy that showed the rough surfaces on the carbon samples. The use of fabricated activated carbon for removal of eosin dye from aqueous solutions at different contact time, initial dye concentration, $\mathrm{pH}$ and adsorbent doses was investigated. The experimental results show that the adsorption process attains equilibrium within 20 min. The adsorption isotherm equilibrium was studied by means of the Langmuir and Freundlich isotherms, and it was found that the data fit the Langmuir isotherm equation with maximum monolayer adsorption capacity of $126.58 \mathrm{mg} \mathrm{g}^{-1}$. The results indicated that the home made activated carbon prepared from palm trunks has the ability to remove eosin dye from aqueous solution and it will be a promising adsorbent for the removal of harmful dyes from waste water.
\end{abstract}

\section{Keywords}

Activated carbon; Date palm trunks; $\mathrm{H}_{3} \mathrm{PO}_{4}$ activation; Adsorption; Dye removal; Eosin dye; Isotherm.

\section{Council for Innovative Research}

Peer Review Research Publishing System

\section{Journal: Journal of Advances in Chemistry}

\author{
Vol. 10, No. 4 \\ editorjaconline@gmail.com
}




\section{INTRODUCTION}

Dyes are commonly utilized for coloring textiles, wool, and other materials. These dyes are from coal-tar based hydrocarbons such as benzene, naphthalene, anthracene, toluene, and xylene [1]. These pollutants are difficult to decolorize because of their complex aromatic structure and synthetic origin [2]. Although the exact number of the produced dyes in the world is not known, there are estimated to be more than 100,000 different available dyes. Many of them are known to be toxic or carcinogenic [2-5]. Commonly, these dyes are discharged in the environment in form of colored waster water by many industries without any prior treatment [2].

Purification of waste water from dyes is becoming increasingly important. There are several methods that have been utilized for the removal of dyes from waste water. For example, adsorption [6-8], nanofiltration [9], ozonation [10], and electroflotation [11]. All of these processes have different capabilities for removing dyes. Among these methods, adsorption has been found to be the best technique for waste water purification. The reasons for these are the simplicity of the procedure, ease of operation, and insensitivity of toxic substances [11].

Activated carbon (AC) is commonly the most popular adsorbent. It has the ability to adsorb many dyes with high capacity because of its high surface area [12-15]. However, its application is restricted because it is very expensive and the price of regeneration of the activated carbon is expensive due to the difficulty of desorption of the dye molecules from the activated carbon [16]. Therefore, many studies have focused on preparation of activated carbon from cheaper and renewable raw materials, which are commonly an agricultural byproduct [17]. The raw materials that have been used for fabrication of activated carbon are rice hull [18], olive cake [19], corncob [20], coconut husk [21], rattan sawdust [22], and bagasse bottom ash [23].

Generally, fabrication of activated carbons involves two steps: pyrolysis, and physical and/or chemical activation [24]. In terms of the chemical activation, it involves using dehydrating chemical agents such as $\mathrm{ZnCl}_{2}, \mathrm{H}_{3} \mathrm{PO}_{4}$, and $\mathrm{H}_{2} \mathrm{SO}_{4}$. The most common preferred chemical agent is $\mathrm{H}_{3} \mathrm{PO}_{4}$ because it is recoverable and the temperature of the activation is relatively low (around $400-500^{\circ} \mathrm{C}$ ) $[17,25]$.

The main objective of this study is to investigate the preparation of activated carbon from the trunks of date palms by $\mathrm{H}_{3} \mathrm{PO}_{4}$ activation. This plant is inexpensive and widespread throughout Saudi Arabia and other parts of the world, such as United States of America, the Canary Islands, northern Africa, the Middle East, Pakistan, and India. In addition, this contribution is investigating removing of eosin dye from aqueous solution in order to evaluate the capacity of the prepared activated carbon. The equilibrium data of adsorption studies were processed to understand the adsorption mechanism of the dye molecules onto the activated carbon.

\section{Experimental}

\subsection{Chemicals and Materials}

Date plam trunks were collected from a local garden near Taif, KSA. Whatman filter paper (diam. 15 mm) was purchased from Sigma-Aldrich (Nottingham, UK). Eosin dye (99\%) was purchased from Sigma-Aldrich (Nottingham, UK) and used without further purification. Distilled water was employed for preparing all the solutions and reagents.

\subsection{Instrumentation}

A pH meter (Fisherman Hydrus 300, Thermo Orion, Beverly, MA, USA), a hot plate-stirrer from VWR International LLC (West Chester, PA, USA), a scanning electron microscope (SEM) Cambridge S360 from Cambridge Instruments (Cambridge, UK), UV-Vis spectrophotometer from Thermo Scientific ${ }^{\text {TM }}$ GENESYS 10S (Toronto, Canada), a furnace (WiseTherm high temperature muffle furnaces, Wisd Laboratory Instrument, Wertheim, Germany).

\subsection{Preparation and Characterization of Activated Carbon}

Figure 1 illustrates the steps that were used for fabrication of the activated carbon from date palm trunks. The collected palm trunks were washed with distilled water, dried in sunlight for $24 \mathrm{~h}$, and ground. The dried palm trunks powder was sieved to $250-500 \mu \mathrm{m}$ in size. Then, it was soaked with a boiling solution of $63 \% \mathrm{H}_{3} \mathrm{PO}_{4}$. After $24 \mathrm{~h}$, the excess amount of solution decanted off and air dried. The material was carbonized at $400{ }^{\circ} \mathrm{C}$ for 30 min using a muffle furnace. The dried material was activated in a muffle furnace at $800{ }^{\circ} \mathrm{C}$ for $10 \mathrm{~min}$. Subsequently, the carbonized material produced was taken out and washed with plenty of distilled water to remove the residual acid. It was dried at $60{ }^{\circ} \mathrm{C}$ for $24 \mathrm{~h}$ and stored. The surface morphology of prepared material was observed by scanning electron microscopy (SEM), and the sample was gold coated prior to SEM observation. 


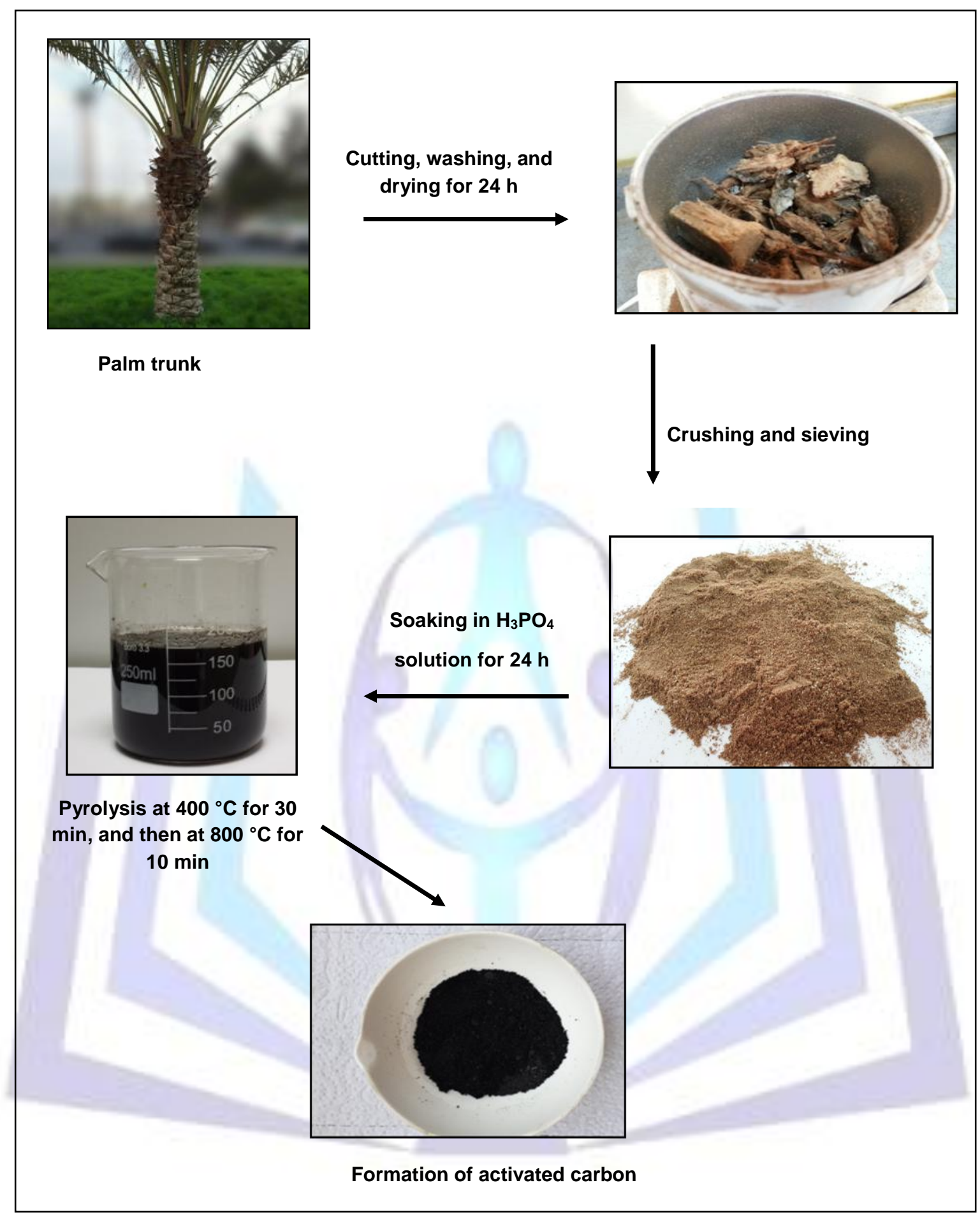

Fig 1: The process carried out on fabrication of activated carbon from date palm trunks.

\subsection{Removing of Eosin Dye From Aqueous Solution}

\subsubsection{Effect of Contact Time and Dye Concentration}

A stock solution of eosin dye of $20 \mathrm{mg} \mathrm{L}^{-1}$ was prepared, which was diluted to the required initial concentrations. Adsorption isotherms were performed in a set of 43 Erlenmeyer flask $(250 \mathrm{~mL})$. The effect of contact time on removal of eosin dye was studied for a period of $50 \mathrm{~min}$. The adsorption experiments were carried out by agitating $0.2 \mathrm{~g}$ of adsorbent (activated carbon fabricated from palm trunk) with different concentrations of eosin dye $\left(2,5,10\right.$, and $\left.20 \mathrm{mg} \mathrm{L}^{-1}\right)$ at different conical flask and kept in an isothermal shaker at 200 rotation per minute $(200 \mathrm{rpm})$, for each of the different contact times $(5,10,15,20,30,40$, and $50 \mathrm{~min})$. The flasks were then removed from the shaker and the sample solutions were filtered using filter paper before analysis to minimize the interference of the carbon fines with the analysis. The 
performance of the fabricated activated carbon in terms of removing of dye from aqueous solution was checked by monitoring the absorbance changes at a wavelength of maximum absorbance (517 nm) using a UV-Vis spectrophotometer [16]. The amount of adsorbed eosin dye was calculated using the following mass balance equation:

$$
q_{e q}=\frac{\left(C_{\mathrm{i}}-C_{e q}\right) V}{1000 \mathrm{~m}}[26]
$$

Where $q_{e q}$ is the amount of dye adsorbed $\left(\mathrm{mg} \mathrm{g}^{-1}\right), C_{i}$ is the initial dye concentration $\left(\mathrm{mg} \mathrm{L}^{-1}\right), C_{e q}$ is the equilibrium dye concentration ( $\left.\mathrm{mg} \mathrm{L}^{-1}\right), V$ is the volume of solution $(\mathrm{mL})$, and $m$ is the mass of activated carbon sample $(\mathrm{mg})$.

\subsubsection{Effect of Adsorbent Dosage}

Different dosages of the adsorbents $(0.2,0.4,0.6,0.8$, and $1 \mathrm{~g})$ were added in different conical flasks containing $50 \mathrm{~mL}$ of the dye $\left(10 \mathrm{mg} \mathrm{L}^{-1}\right)$, agitated in a shaker for $50 \mathrm{~min}$ at a speed of $200 \mathrm{rpm}$ at a room temperature of $25^{\circ} \mathrm{C}$. The content of each flask was then filtered and analyzed after the agitation time.

\subsubsection{Effect of $\mathrm{pH}$}

The effect of the solution $\mathrm{pH}$ on eosin dye removal was investigated similary as described above by changing the initial $\mathrm{pH}$ (1-11), and the $\mathrm{pH}$ was adjusting by $0.1 \mathrm{M} \mathrm{HCl}$ solution or $0.1 \mathrm{M} \mathrm{NaOH}$ solution. For this particular study, $50 \mathrm{~mL}$ of eosin dye $\left(10 \mathrm{mg} \mathrm{L}^{-1}\right)$ was added to $0.6 \mathrm{~g}$ of the activated carbon into different $250 \mathrm{~mL}$ conical flask and agitated at $200 \mathrm{rpm}$ for 50 min. Each experiment was duplicated under identical conditions. Langmuir and Freundlich isotherms were employed to study the adsorption capacity of the adsorbent.

\section{RESULTS AND DISCUSSION}

\subsection{Fabrication of The Activated Carbon}

The purpose of this study was to investigate fabrication of activated carbon from available raw materials. In this study, the activated carbon was fabricated from palm trunks since the date palms are abundant and inexpensive natural resource in Saudi Arabia. The palm trunks-based activated carbon was fabricated using activating agents that was phosphoric acid solution. The reason for choosing this activated agent is that phosphoric acid solution can produce activated carbon with high porosity $[27,28]$. The morphology of the fabricated activated carbon was studied using SEM instrument. Figure 2 shows the appearance of the fabricated activated carbon using different magnifications. The SEM micrographs indicated that the fabricated material had cavities, and rough surfaces on the carbon samples. These micrographs confirmed that the fabricated material had high porosity, which can hold more solute from the solution during adsorption [28].
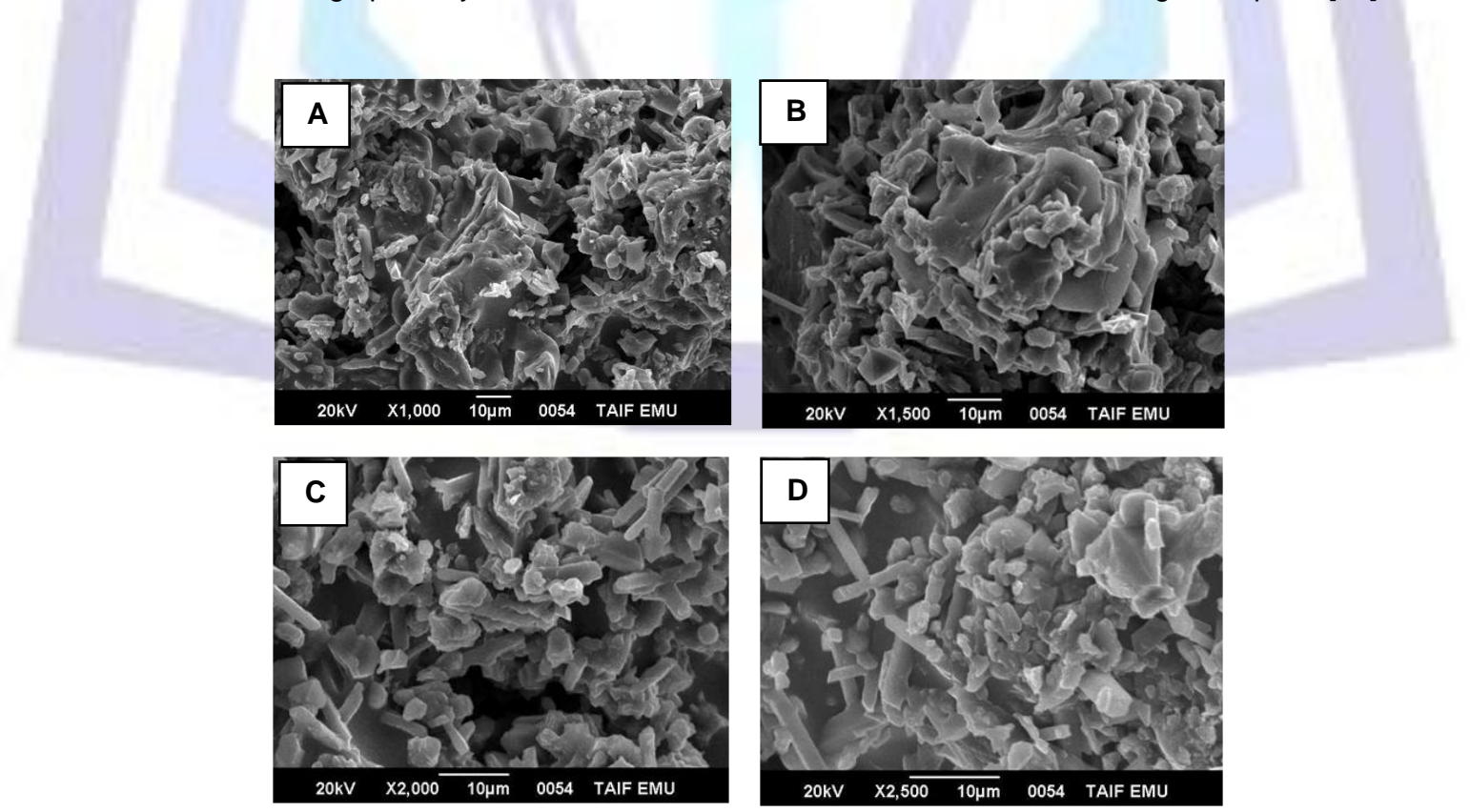

Fig 2: SEM micrographs of the fabricated activated carbon using different magnifications: $(A) 1000 \times,(B) 1500 \times$, (C) $2000 \times$, and (D) $2500 \times$. 


\subsection{Effect of Contact Time and Dye Concentration on Adsorption of Eosin Dye}

In this study, eosin dye was used in order to check the ability of the prepared activated carbon to remove dyes from aqueous solution. Eosin dye is the most commonly used material for dying cotton, wood, and silk due to its vivid colour [29]. The most important parameter such as contact time, initial concentration, sorbent dosage, and pH on adsorption of eosin dye were studied.

The effect of agitation time and concentration of dye on adsorption was investigated. A series of contact time experiments for eosin dye have been carried out at different concentrations $\left(2-20 \mathrm{mg} \mathrm{L}^{-1}\right)$ and at room temperature of $25^{\circ} \mathrm{C}$, at intervals of $50 \mathrm{~min} .50 \mathrm{~mL}$ of dye was mixed with $0.2 \mathrm{~g}$ of the activated carbon, followed by filtration of the solution using the filter paper. The performance of the activated carbon was examined using UV-Vis spectrophotometer at $517 \mathrm{~nm}$. The relationship between contact time and the percentage removal of eosin dye from aqueous solution with activated carbon produced from palm trunks is shown in figure 3. From the obtained results, it can be seen that the removal of dye increased as contact time increase. With increase in contact time, the external mass transfer coefficient increase, resulting in quicker adsorption of the dye molecules by the activated carbon. However, the adsorption capacity gradually increases until equilibrium is reached at $20 \mathrm{~min}$. At this point, the amount of eosin dye adsorbed onto the adsorbent (activated carbon) is in state of dynamic equilibrium with the amount of the dye desorbing from the adsorbent. The time required to attain this state of equilibrium is called the equilibrium time. The amount of eosin dye adsorbed at the equilibrium time reflects the maximum adsorption capacity of the adsorbent under those operating conditions. A similar trend has been reported in literature $[16,30]$. The adsorption density at equilibrium increased with increase in the initial dye concentration from 2 to $20 \mathrm{mg} \mathrm{L}^{-1}$ from 8 to $47 \mathrm{mg} \mathrm{g}^{-1}$.

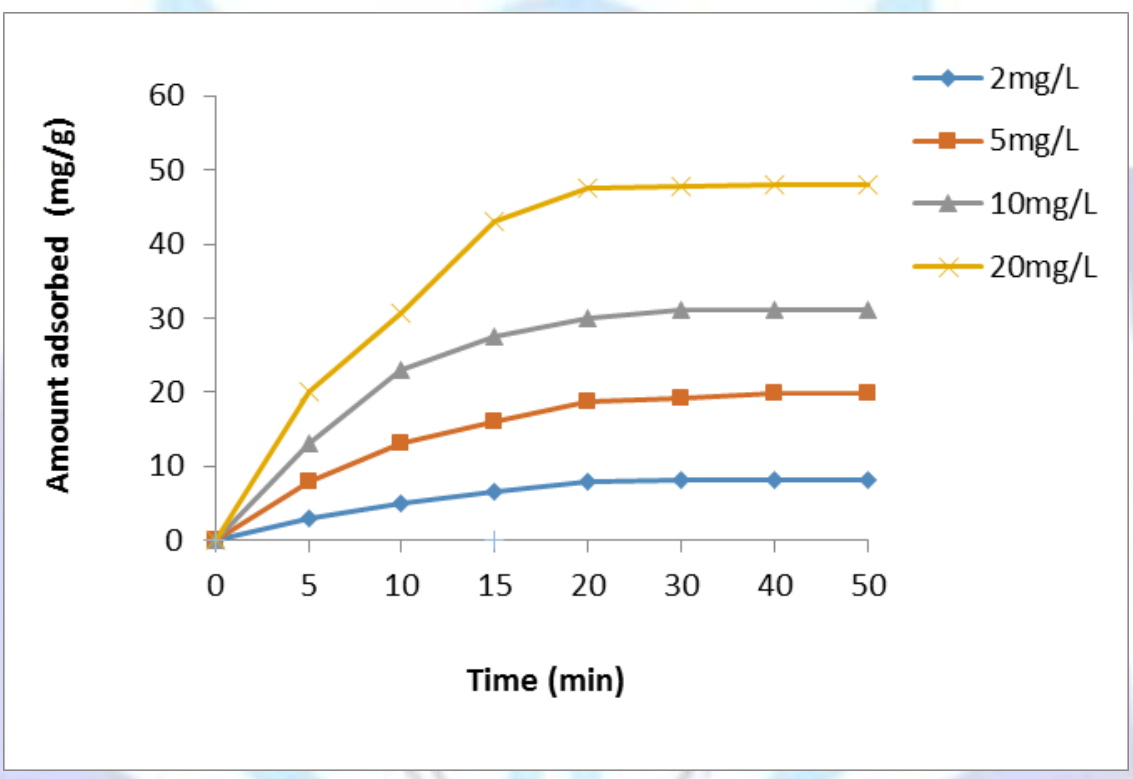

Fig 3: The variation of adsorption capacity with contact time at various initial dye concentration at $25^{\circ} \mathrm{C}$ (adsorbent $\left.=0.2 \mathrm{~g}, \mathrm{~V}=50 \mathrm{~mL}\right)$.

The SEM images of the activated carbon after adsorption of eosin dye molecules were studied. Figure 4 shows the SEM micrographs of the activated carbon after adsorption of eosin dye $\left(10 \mathrm{mg} \mathrm{L}^{-1}\right)$ and the agitation time was $50 \mathrm{~min}$. From the images, it can be seen that the microstructure of the prepared activated carbon was changed and the cavities and roughness surface of the activated carbon were decreased due to the adsorption of the dye on the surface of the activated carbon. This investigation showed that palm trunks can be an effective material for preparation of activated carbon in order to use it as an adsorbent for removing of eosin dye from aqueous solution.

\subsection{Effect of Adsorbent Dosage}

The effect of the activated carbon dosage on removal of dye was investigated. In this study, adsorbent dosage was varied from 0.2 to $1 \mathrm{~g}$, under the specific conditions $\left(50 \mathrm{~mL}\right.$ of eosin dye $\left(10 \mathrm{mg} \mathrm{L}^{-1}\right)$, contact time of $50 \mathrm{~min}, 200 \mathrm{rpm}$ shaking speed, and at room temperature of $25^{\circ} \mathrm{C}$ ). Figure 5 shows the effect of adsorbent dosage on removal of eosin dye by the fabricated activated carbon. From the figure, it can be seen that the adsorbance of the eosin dye increased as the adsorbent dosage increased, which is due to the increase in absorbent surface area of the adsorbent [1]. 

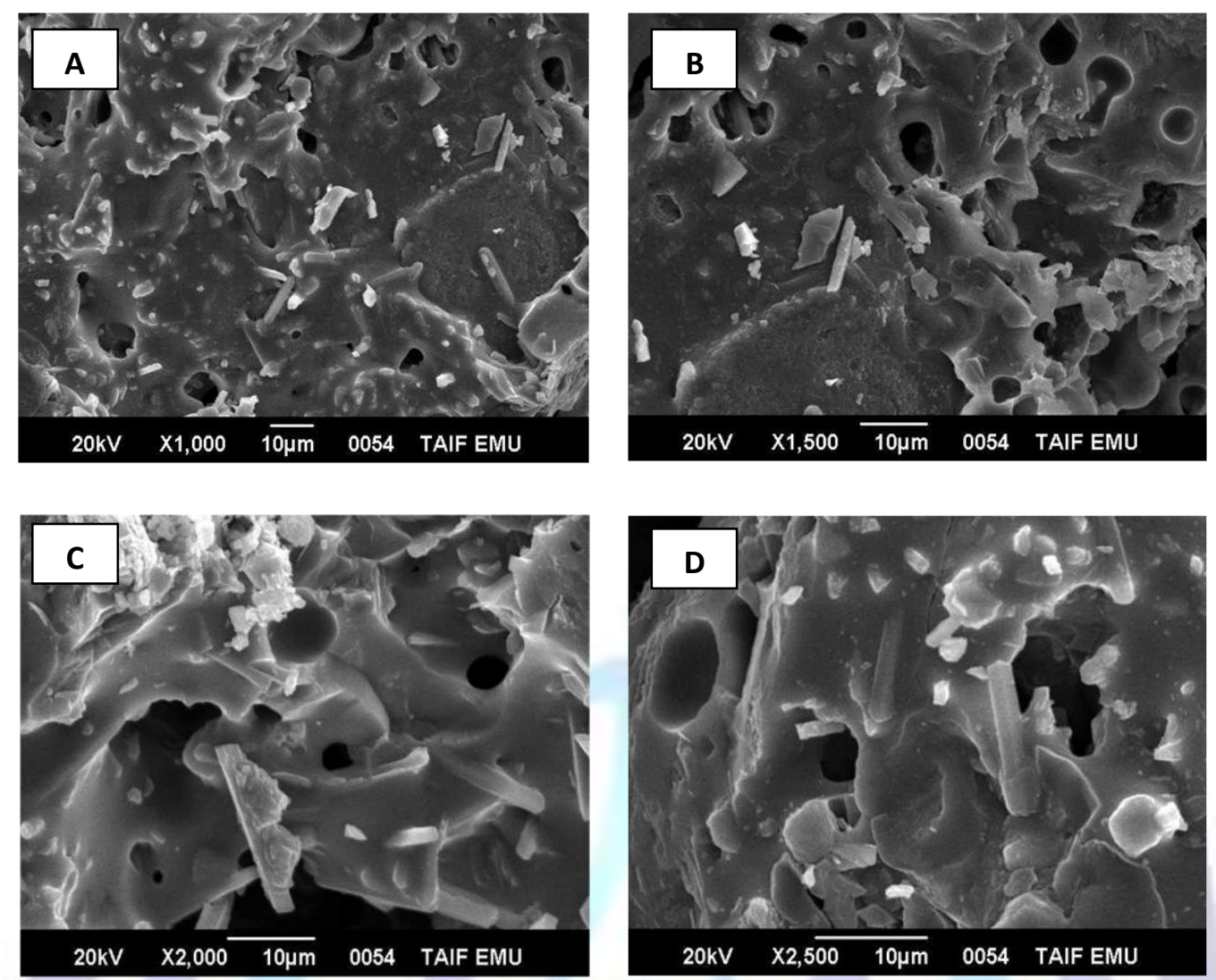

Fig 4: SEM micrographs of the fabricated activated carbon after adsorption of eosin dye molecules using different magnifications: (A) $1000 \times$, (B) $1500 \times$, (C) $2000 \times$, and (D) $2500 \times$.

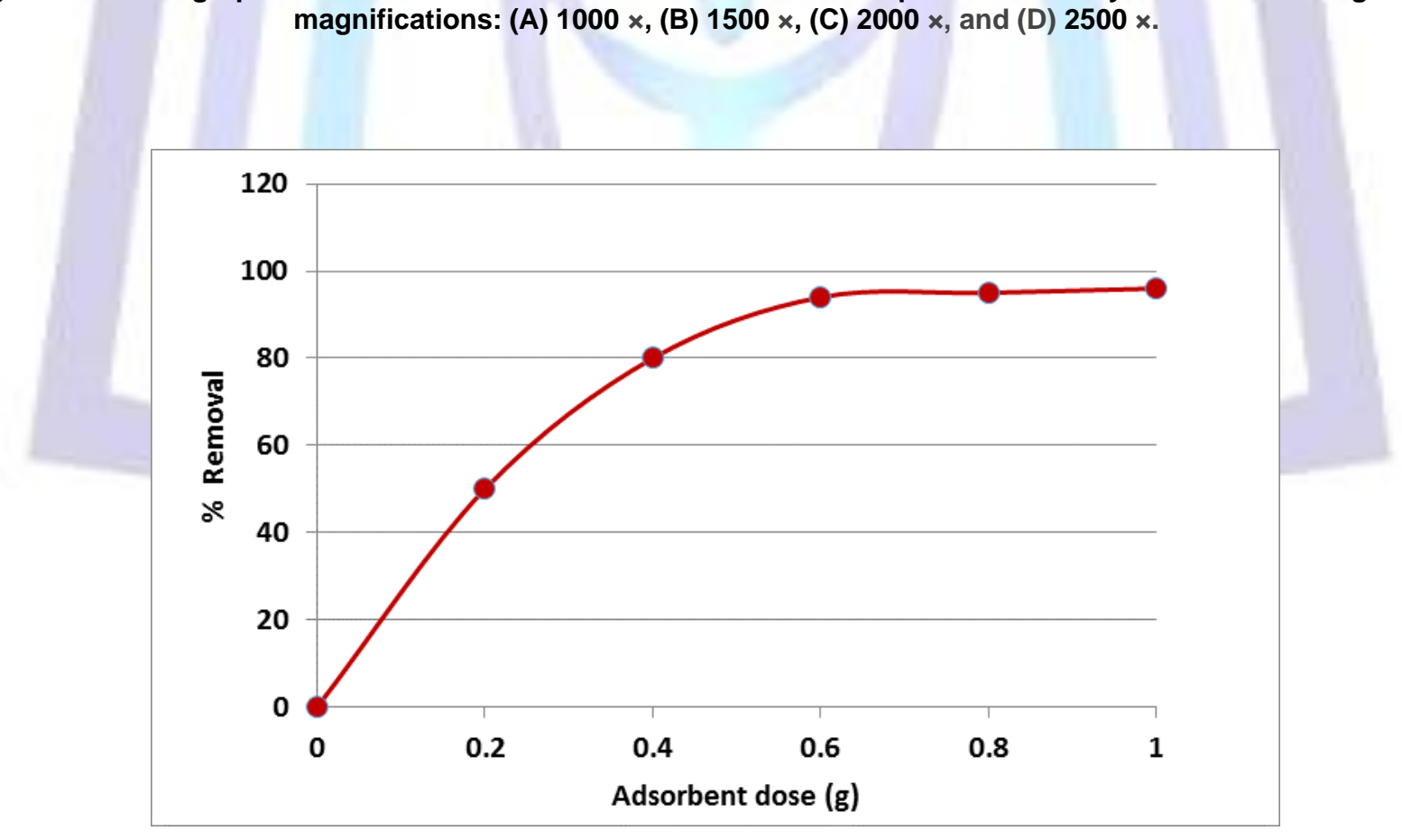

Fig 5: Effect of adsorbent dosage on removal of eosin dye; agitation time (50 min), $50 \mathrm{~mL}$ of eosin dye $\left(10 \mathrm{mg} \mathrm{L}^{-1}\right)$. 


\subsection{Effect of $\mathrm{pH}$}

The $\mathrm{pH}$ of the dye solution plays an important role in the adsorption process especially on adsorption capacity [6]. In this study, the adsorption of eosin dye was tested in different $\mathrm{pH}$ values 1-11 using dilute $\mathrm{HCl}$ or $\mathrm{NaOH}$ solutions with keeping other parameters constant. The effect of $\mathrm{pH}$ on the adsorption of eosin dye by the fabricated activated carbon is presented in figure 6 . From the figure, it can be seen that the $\mathrm{pH}$ of the solution affects the amount of dye adsorbed. At lower $\mathrm{pH}$, the surface of the adsorbent becomes positively charged due to the high concentration of $\mathrm{H}^{+}$ions, which enhances the adsorption of the negatively changed eosin dye (anionic dye) through electrostatic forces attraction. In contrast, in alkaline conditions the surface of the adsorbent is negatively charged due to the high concentration of $\mathrm{OH}^{-}$ions on the surface of the adsorbent competing with the eosin dye for adsorption sites. A similar trend was observed for adsorption of eosin dye onto fly ash [16].

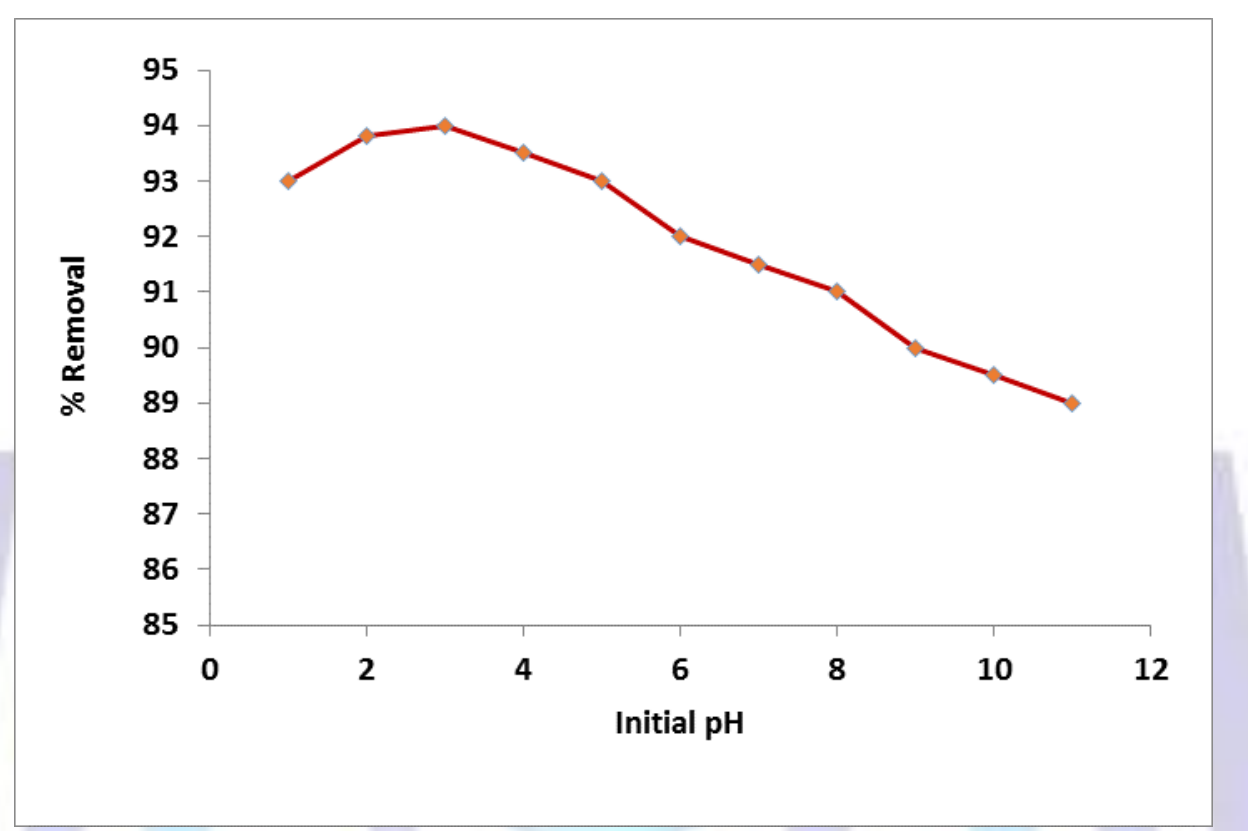

Fig 6: Effect of pH on removal of eosin dye by the prepared activated carbon from palm trunks, adsorbent dose $(0.6 \mathrm{~g})$ agitation time $50 \mathrm{~min} ; 50 \mathrm{~mL}$ of eosin dye $\left(10 \mathrm{mgL}^{-1}\right)$.

\subsection{Adsorption Isotherms Studies}

The adsorption isotherm describes how adsorbates interact with adsorbents. The equilibrium adsorption isotherm can be graphically depicted by plotting a solid phase against a liquid phase concentrations. Several isotherm equations are available. In this study, the adsorption equilibrium data of eosin dye onto the palm trunk-based activated carbon were analyzed in terms of Langmuir and Freundlich isotherm models. The applicability of the isotherm equation is compared by judging the correlation coefficients $\left(R^{2}\right)[30]$.

\subsubsection{Langmuir Adsorption Isotherm}

Langmuir adsorption isotherm assumes that the adsorption of adsorbates occur on specific homogeneous surface by monolayer adsorption without any interaction between adsorbed species. The Langmuir adsorption isotherm equation as the following equation:

$$
\frac{c_{e q}}{q_{e}}=\frac{1}{K b}+\frac{c_{e q}}{b}
$$

Where $C_{e q}$ is the dye concentration remaining in the solution at equilibrium ( $\mathrm{mg} \mathrm{L}^{-1}$ ), $q_{e}$ is the amount of solute adsorbed per unit weight of adsorbent $\left(\mathrm{mg} \mathrm{g}^{-1}\right), K$ is the maximum adsorption capacity corresponding to complete monolayer coverage $\left(\mathrm{mg} \mathrm{g}^{-1}\right)$, and $b$ is the Langmuir isotherm constant $\left(\mathrm{L} \mathrm{mg}^{-1}\right)$. A plot of $\frac{c_{\mathrm{qq}}}{q_{\mathrm{q}}}$ versus $C_{\mathrm{eq}}$ gave a straight line with a slope $\frac{1}{K b}$ and an intercept of $\frac{1}{b}$ (figure 7). From the figure, it can be seen that the adsorption of the eosin dye on the activated carbon follows the Langmuir isotherm. Values of $K$ and $b$ were calculated from the slope and intercept of the linear plots and presented in Table 1. The applicability of the Langmuir isotherm suggests the monolayer coverage of the dye on the surface of the palm trunk-based activated carbon. 


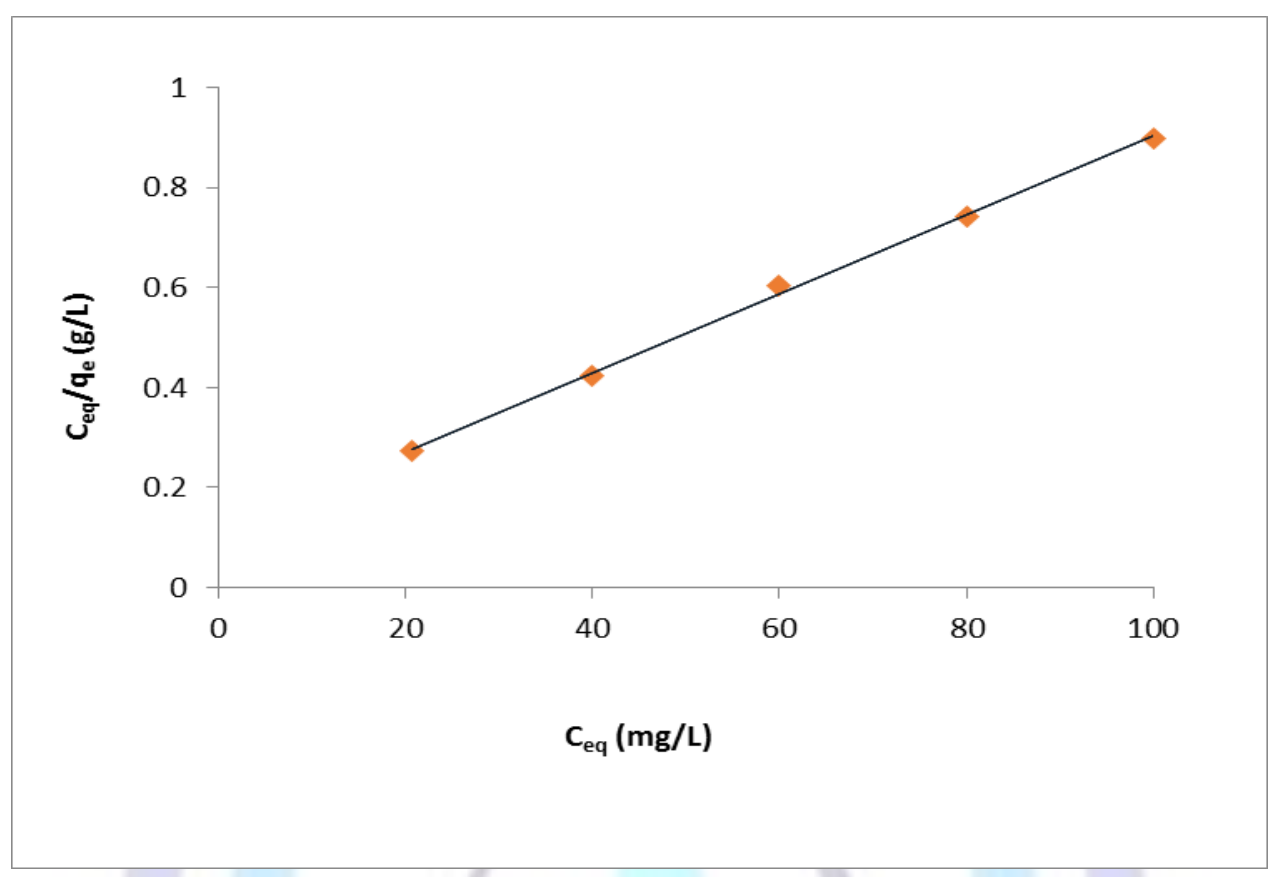

Fig 7: Plot of Langmuir adsorption isotherm of eosin dye onto powdered activated carbon.

The essential characteristic of the Langmuir isotherm can be expressed by a dimensionless constant called equilibrium parameter $\left(R_{\mathrm{L}}\right)$, which can be defined by:

$$
R_{L}=\frac{1}{\left(1+b c_{\varepsilon}\right)}[7]
$$

Where $b$ is the Langmuir isotherm constant $\left(\mathrm{L} \mathrm{mg}^{-1}\right), C_{e}$ is the initial dye concentration $\left(\mathrm{mg} \mathrm{L}^{-1}\right)$, and $R_{L}$ value indicates the type of isotherm. $R_{L}$ can be either unfavourable if $R_{L}>1$, linear if $R_{L}=1$, favourable if $0<R_{L}<1$, and irreversible if $R_{L}=0$ $[30,31]$. As seen from Table 1 , the $R_{L}$ values were found to be between 0 and 1 for dye concentrations of 2, 5, 10, and 20 $\mathrm{mg} \mathrm{L}^{-1}$. In this work, the maximum monolayer coverage capacity $(K)$ from Langmuir isotherm was calculated to be 126.58 $\mathrm{mg} \mathrm{g}^{-1}$, (b) was $0.069 \mathrm{~L} \mathrm{mg}^{-1}$, the $R^{2}$ value is 0.998 indicating a very good mathematical fit and the activated carbon is favorable for adsorption of eosin dye under conditions used in this study.

Table 1: Langmuir isotherm constants for eosin dye.

\begin{tabular}{|c|c|c|c|c|}
\hline Dye concentration $\left(\mathbf{m g ~ L}^{-1}\right)$ & $K\left(\mathbf{m g ~ g}^{-1}\right)$ & $b\left(\mathbf{L ~} \mathbf{g ~}^{-1}\right)$ & $R^{2}$ & $R_{L}$ \\
\hline 2 & 126.58 & 0.069 & 0.998 & 0.878 \\
\hline 5 & & & & 0.743 \\
\hline 10 & & & & 0.591 \\
\hline 20 & & & & 0.420 \\
\hline
\end{tabular}

\subsubsection{Freundlich Adsorption Isotherm}

Freundlich adsorption isotherm assumes that the adsorption of adsorbates occurs on heterogenous adsorption surface by multilayer adsorption and that the amount of adsorbate adsorbed increases infinitely with an increase in concentration. The linearized form of Freundlich model is represented by the following equation:

$$
\log q_{e}=\log k_{f}+\left(\frac{1}{n}\right) \log C_{e}
$$


where $q_{e}$ is the amount of eosin dye adsorbed at equilibrium $\left(\mathrm{mg} \mathrm{g}^{-1}\right), C_{e}$ is the equilibrium constant of the adsorbate (mg $\left.\mathrm{L}^{-1}\right), k_{f}$ and $\frac{1}{n}$ are Freundlich constants incorporating the factors affecting the sorption capacity and the degree of nonlinearity between the dye concentration in the solution and the amount adsorbed at equilibrium, respectively, and they can be obtained from the intercept and slope of $\log q_{e}$ versus $\log C_{e}$ plot. As can be seen in figure 8 , the linear plot of $\log q_{e}$ vs $\log C_{e}$ indicates that the adsorption of eosin dye also follows the Freundlich adsorption isotherm. The slope $\left(\frac{1}{n}\right)$ ranging between zero and one is a measure of adsorption intensity or surface heterogeneity and becoming more hetero heterogeneous as its value gets closer to zero. A value for $\left(\frac{1}{n}\right)$ below 1 indicates a normal Langmuir isotherm while $\left(\frac{1}{n}\right)$ above 1 is indicative of cooperative adsorption [32]. In this study, the value of $\frac{1}{n}$ was 0.240 indicating that the adsorption of eosin dye also follows Freundlich isotherm. However, $R^{2}$ value of Langmuir isotherm was compared with those of Freundlich isotherm, and it was found that the Langmuir isotherm yields a somewhat better fit $\left(R^{2}=0.998\right)$ than the Freundlich isotherm $\left(R^{2}=0.975\right)$.

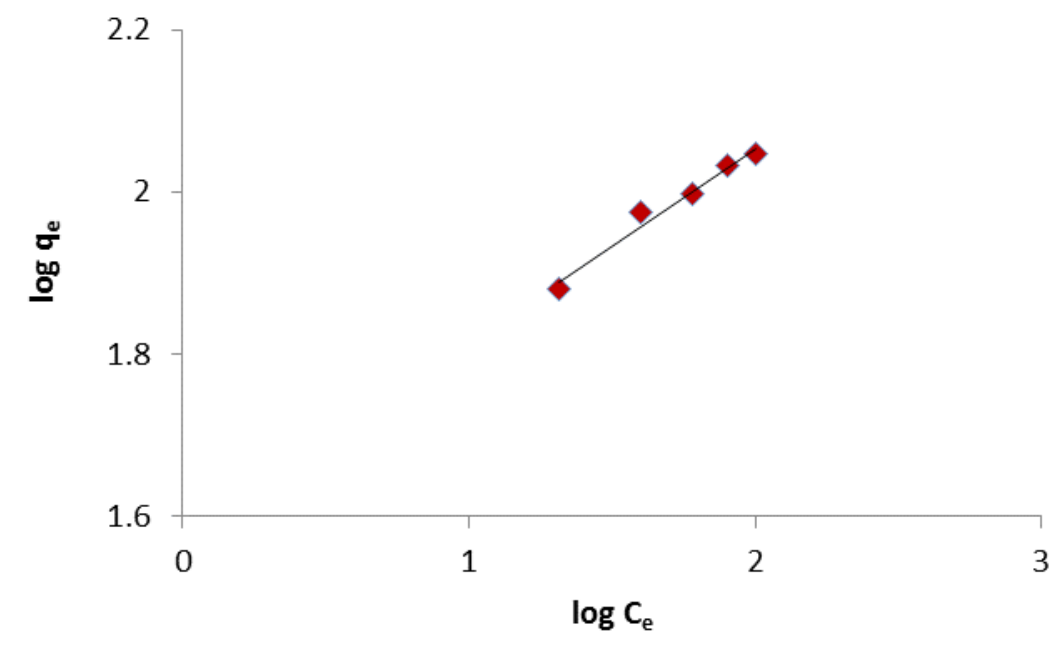

Fig 8: Freundlich isotherm plot of the adsorption of eosin dye onto activated carbon.

\section{CONCLUSION}

From the results of the present investigation, the home made activated carbon has been fabricated successfully from date palm trunks. Eosin dye had been used to check the performance of the fabricated activated carbon. The results indicated that the fabricated activated carbon from palm trunks has the ability to remove eosin dye from aqueous solution, which was confirmed by UV-Vis spectrophotometer. The equilibrium data followed the Langmuir isotherm and the maximum monolayer adsorption capacities of $126.58 \mathrm{mg} \mathrm{g}^{-1}$. In conclusion, palm trunks are a potential and low-cost natural material for the preparation of activated carbon. A future study investigating the removal of dyes from a real sample such as waste water would be interesting.

\section{REFERENCES}

[1] Namasivayam, C. and D. Kavitha, Removal of Congo Red from water by adsorption onto activated carbon prepared from coir pith, an agricultural solid waste. Dyes and Pigments, 2002. 54(1): p. 47-58.

[2] Mahmoodi, N.M., R. Salehi, and M. Arami, Binary system dye removal from colored textile wastewater using activated carbon: Kinetic and isotherm studies. Desalination, 2011. 272(1-3): p. 187-195.

[3] Robinson, T., et al., Remediation of dyes in textile effluent: a critical review on current treatment technologies with a proposed alternative. Bioresource Technology, 2001. 77(3): p. 247-255. 
[4] Gómez, V., M.S. Larrechi, and M.P. Callao, Kinetic and adsorption study of acid dye removal using activated carbon. Chemosphere, 2007. 69(7): p. 1151-1158.

[5] Crini, G. and P.-M. Badot, Application of chitosan, a natural aminopolysaccharide, for dye removal from aqueous solutions by adsorption processes using batch studies: A review of recent literature. Progress in Polymer Science, 2008. 33(4): p. 399-447.

[6] Bulut, Y. and H. Aydın, A kinetics and thermodynamics study of methylene blue adsorption on wheat shells. Desalination, 2006. 194(1-3): p. 259-267.

[7] Mahmoodi, N.M., et al., Novel biosorbent (Canola hull): Surface characterization and dye removal ability at different cationic dye concentrations. Desalination, 2010. 264(1-2): p. 134-142.

[8] Uğurlu, M., Adsorption of a textile dye onto activated sepiolite. Microporous and Mesoporous Materials, 2009. 119(13): p. 276-283.

[9] Chakraborty, S., et al., Treatment of a textile effluent: application of a combination method involving adsorption and nanofiltration. Desalination, 2005. 174(1): p. 73-85.

[10] Erol, F. and T.A. Özbelge, Catalytic ozonation with non-polar bonded alumina phases for treatment of aqueous dye solutions in a semi-batch reactor. Chemical Engineering Journal, 2008. 139(2): p. 272-283.

[11] Amin, N.K., Removal of direct blue-106 dye from aqueous solution using new activated carbons developed from pomegranate peel: Adsorption equilibrium and kinetics. Journal of Hazardous Materials, 2009. 165(1-3): p. 52-62.

[12] Baccar, R., et al., Preparation of activated carbon from Tunisian olive-waste cakes and its application for adsorption of heavy metal ions. Journal of Hazardous Materials, 2009. 162(2-3): p. 1522-1529.

[13] Kadirvelu, K., et al., Utilization of various agricultural wastes for activated carbon preparation and application for the removal of dyes and metal ions from aqueous solutions. Bioresource Technology, 2003. 87(1): p. 129-132.

[14] Mall, I.D., et al., Removal of congo red from aqueous solution by bagasse fly ash and activated carbon: Kinetic study and equilibrium isotherm analyses. Chemosphere, 2005. 61(4): p. 492-501.

[15] Choy, K.K.H., J.F. Porter, and G. McKay, Intraparticle diffusion in single and multicomponent acid dye adsorption from wastewater onto carbon. Chemical Engineering Journal, 2004. 103(1-3): p. 133-145.

[16] Bello, O.S., O.A. Olusegun and V.O. Njoku, Fly ash; an alternative to powdered activated carbon for the removal of eosin dye from aqueous solutions. Bull. Chem. Soc. Ethiop. ,, 2013. 27(2): p. 191-204.

[17] Shi, Q., et al., Preparation of activated carbon from cattail and its application for dyes removal. Journal of Environmental Sciences, 2010. 22(1): p. 91-97.

[18] Guo, Y. and D.A. Rockstraw, Activated carbons prepared from rice hull by one-step phosphoric acid activation. Microporous and Mesoporous Materials, 2007. 100(1-3): p. 12-19.

[19] Aljundi, I. and N. Jarrah, A study of characteristics of activated carbon produced from Jordanian olive cake. Journal of Analytical and Applied Pyrolysis, 2008. 81(1): p. 33-36.

[20] Tseng, R.L., S.K. Tseng, and F.C. Wu, Preparation of high surface-area carbons from corncob with $\mathrm{KOH}$ etching plus CO2 gasification for the adsorption of dyes and phenols from water. Colloids and Surfaces A: Physicochemical and Engineering Aspects, 2006. 1: p. 69-78.

[21] Tan, I.A.W., A.L. Ahmad, and B.H. Hameed, Adsorption of basic dye on high-surface-area activated carbon prepared from coconut husk: Equilibrium, kinetic and thermodynamic studies. Journal of Hazardous Materials, 2008. 154(1-3): p. 337-346.

[22] Hameed, B.H., L.H. Chin, and S. Rengaraj, Adsorption of 4-chlorophenol onto activated carbon prepared from rattan sawdust. Desalination, 2008. 225(1-3): p. 185-198.

[23] Aworn, A., P. Thiravetyan, and W. Nakbanpote, Preparation and characteristics of agricultural waste activated carbon by physical activation having micro- and mesopores. Journal of Analytical and Applied Pyrolysis, 2008. 82(2): p. 279285.

[24] Uğurlu, M., A. Gürses, and M. Açıkyıldız, Comparison of textile dyeing effluent adsorption on commercial activated carbon and activated carbon prepared from olive stone by $\mathrm{ZnCl} 2$ activation. Microporous and Mesoporous Materials, 2008. 111(1-3): p. 228-235.

[25] Guo, Y. and D.A. Rockstraw, Physical and chemical properties of carbons synthesized from xylan, cellulose, and Kraft lignin by H3PO4 activation. Carbon, 2006. 44(8): p. 1464-1475.

[26] Salima, A., et al., Application of Ulva lactuca and Systoceira stricta algae-based activated carbons to hazardous cationic dyes removal from industrial effluents. Water Research, 2013. 47(10): p. 3375-3388.

[27] McDougall, G., The physical nature and manufacture of activated carbon. Journal of the South African Institute of Mining and Metallurgy, 1991. 91(4): p. 109-120. 
[28] Baseri, J.R., P. Palanisamy, and P. Sivakumar, Comparative Studies of the Adsorption of Direct Dye on Activated Carbon and Conducting Polymer Composite. Journal of Chemistry, 2012. 9(3): p. 1122-1134.

[29] Ansari, R. and Z. Mosayebzadeh, Removal of Eosin Y, an anionic dye, from aqueous solutions using conducting electroactive polymers. Iranian Polymer Journal, 2010. 19(7): p. 541-551.

[30] Hameed, B., A.M. Din, and A. Ahmad, Adsorption of methylene blue onto bamboo-based activated carbon: kinetics and equilibrium studies. Journal of hazardous materials, 2007. 141(3): p. 819-825.

[31] Salehi, R., et al., Novel biocompatible composite (Chitosan-zinc oxide nanoparticle): Preparation, characterization and dye adsorption properties. Colloids and Surfaces B: Biointerfaces, 2010. 80(1): p. 86-93.

[32] Fytianos, K., E. Voudrias, and E. Kokkalis, Sorption-desorption behaviour of 2,4-dichlorophenol by marine sediments. Chemosphere, 2000. 40(1): p. 3-6. 